\title{
Biophysical Reviews: slowly getting back to 'normal'?
}

\author{
Damien Hall ${ }^{1,2}$
}

Accepted: 24 March 2021 / Published online: 31 March 2021

(C) International Union for Pure and Applied Biophysics (IUPAB) and Springer-Verlag GmbH Germany, part of Springer Nature 2021

\begin{abstract}
Run by the International Union for Pure and Applied Biophysics (IUPAB) and published by Springer Nature, Biophysical Reviews is an international journal dedicated to publishing topical review articles in the areas of (i) biology-related physics, (ii) structural biology, and (iii) molecular biology. This Editorial for Volume 13, Issue 2 of Biophysical Reviews provides a brief summary of the contents of the current Issue and then describes some matters important to the journal for 2021.
\end{abstract}

Each Issue of Biophysical Reviews is divided into two sections, the front matter section that consists of informative Editorials, Commentaries, and Letters and the review body section, which contains short- and long-form scientific review articles. In this Editorial (Hall 2021), the reader is first provided with a short informal summary of the contributions in these two sections, before then going on to describe the upcoming Special Issues appearing in the journal during 2021. The Editorial concludes with a short explanation of the mechanism for arranging Special Issues (SI) within the journal and lists the benefits available to SI Editors electing to do so.

The first article to immediately follow this Editorial is this Issue's edition of the 'Meet the Editors series' - this time focused on Prof. Addmore Shonhai (University of Venda, South Africa) (Shonhai 2021). As with all of these Meet the Editors scientific biographies, the reader is given both a personal and professional glimpse of the author's life in and around science. Growing up in a country devastated by war, Addmore has had to overcome significantly more challenges than most to become a scientist and establish a successful research career (becoming both Professor and Head of a research institute). Aside from being a fascinating read, the piece highlights Addmore's academic and commercial links with the biophysical, pharmaceutical, and molecular biology communities of

Damien Hall

hall.damien@staff.kanazawa-u.ac.jp; damienhall30@gmail.com

1 WPI Nano Life Science Institute, Kanazawa University, Kakumamachi, Kanazawa, Ishikawa 920-1164, Japan

2 Department of Applied Physics, Alto University, FI-00076 Aalto, Finland
South Africa (Shonhai 2021), and in this regard, it is worth pointing out that he is one of just two members of the Editorial Board located in continental Africa ${ }^{1}$. Over the coming years, the journal hopes to expand its reach into different regions of the world with Africa a key part of this planned future development. Biophysical Reviews would like to thank Prof. Shonhai for his service to date and the journal notes that it is, both lucky to have him, and extremely grateful for his time.

The next article in the front section is a Commentary from the four Special Issue (SI) Editors of the upcoming SI on the $20^{\text {th }}$ International Union for Pure and Applied Biophysics (IUPAB) (Itri et al. 2021). The triennial IUPAB Congress is typically the largest international meeting in the biophysics field with literally thousands of attendees. Acting as both an advisory on the altered nature of this year's meeting as well as a call for submissions for the associated Special Issue, all participants attending or thinking of attending should read this Commentary carefully to see how they may also be able to participate in the SI dedicated to the meeting (Itri et al. 2021).

The final article of the front section is a Letter from Iraq arising from a collaboration between the Department of Physics (University of Basrah) and the Basrah City Public Health Offices (Mohi et al. 2021). This Letter describes the application of multiple laser optical traps to characterize the difference in cellular elasticity of red blood cells isolated from either healthy patients or patients suffering from sickle cell anemia. As an interesting demonstration of physics applied to medicine, this article deserves to be widely read (Mohi et al. 2021).

The first review of Issue 2 is a contribution from four research institutes located near Saarbrücken in Germany (Vesperini et al. 2021). This fascinating article deals with the

\footnotetext{
${ }^{1}$ The other being Prof. Trevor Sewell, University of Cape Town.
} 
topic of 'immune surveillance' - a general term used to describe how immune cells responsible for killing invading pathogens (via phagocytosis ${ }^{2}$ ) both detect their presence and migrate to the site of the pathogen. Concerned with quantifying this behavior in vitro, the bulk of the review describes the results of clever experiments that use microfabrication techniques to create 'mini-obstacle courses' for cultured immune cells, along with methods for observing and recording the timing of their completion (Vesperini et al. 2021).

The second review article contributed from the Haryana region of India (Singh et al. 2021) is concerned with the general topic of sarcopenia (muscle loss) and how the wasting of muscle is regulated via quite complex cross-talk between two signaling pathways respectively responsible for autophagy and ubiquitin directed proteolysis (Ubiquitin-Proteasome System, UPS). This Review discusses correlations between various signaling pathway components and their expression levels and through its exposition highlights the often-real barrier to quantitative/biophysical entry into a complex fieldnamely that some general descriptive model must first be in place (Singh et al. 2021).

The third review article is a collaborative effort from researchers in the UK that concerns antimicrobial vaccines in which signature carbohydrate groups covalently attached to a pathogen's outer membrane are used as the immuno-eliciting agent (Bazhenova et al. 2021). Focusing on vaccine development against diarrhea inducing enteric microbes, Salmonella and Shigella, this Review examines both the determinants of carbohydrate antigenicity (such as peptide-carbohydrate ligation strategies for enhancing antigen presentation and the branch-point chemistry of the carbohydrate itself) as well as biophysical and computational methods for analyzing/ predicting the carbohydrate epitope structure. The use of a flexible carbohydrate as the principal immune-eliciting component represents a different paradigm to the standard proteinbased approach to vaccine development and this review article makes an excellent (and extremely timely) contribution to the discussion of vaccine technology in the current climate (Bazhenova et al. 2021).

The next review is a single-author submission from a research scientist at SCION, one of New Zealand's Crown Research Institutes (CRI), established to advance basic and applied research in biotechnology (Mabbitt 2021). This article deals with the relatively new topic of engineering protein ligation relays - biochemical pathways in which one protein is attached with extreme specificity to another through a cascade of intermediate shuttle protein reactions. In approaching this subject, the author casts a wide historical net, first reviewing

\footnotetext{
${ }^{2}$ Phagocytosis is a process where immune cells (typically glial cells or astrocytes in the brain and neutrophils, macrophages, monocytes, dendritic cells, osteoclasts and eosinophils in the body, engulf a pathogen (or unwanted cell or cell debris) and dissolve it in an internal vacuole known as a phagosome.
}

the simpler related problem of chemical ligation of dyes to certain protein surface groups e.g. amino (lysine) and thiol (cysteines) chemical moieties. As reviewed by the author, the chemistry of such simpler dye ligand covalent attachment problems can be 'improved' through bioengineering, into more complex ligation relay type systems by employing both a bio-recognition element (to direct and mediate the covalent reaction) and a reporter handle (such as green fluorescent protein) that allows localization and quantification of the attached molecule (Mabbitt 2021).

The fifth review provides a focused description of a particular class of broad-spectrum antimicrobial drugs known as sulfonamides (Ovung and Bhattacharyya 2021). Covering the history of their invention, their synthesis and pharmacology, their quantum-level structure, and their current potential as starting blocks in the development of more potent drugs, this review article provides a welcome window through which to better appreciate this somewhat neglected class of drugs (Ovung and Bhattacharyya 2021).

The final review article is a collective effort submitted by scientists from Australia and the UK (Winzor et al. 2021). The topic of this review is concerned with the nature of a correction factor employed in analytical ultracentrifugation (AUC) studies using the sedimentation velocity technique. Since the derivation of the basic theory governing the migration of a dilute solute in a centrifugal field (Svedberg and Nichols 1923; Lamm 1929; Svedberg and Pedersen 1940), an equivalent description at arbitrary concentration has been sought. Experimentally, the question of assessing the concentration dependence would at first seem straightforward, simply involving plotting the average concentration employed in the experiment against the determined parameter (e.g. the sedimentation coefficient). However, all who have done an AUC experiment realize that the concentration changes over time (due to diffusion and heterogeneity) and radius (due to radial dilution) making the exact averaging technique employed a complicated function of the experiment. This review provides a fascinating historical assessment of how this problem has been solved in the past along with descriptions on modern-day approaches (Winzor et al. 2021).

Special issues for 2021 Typically, all special issues (SIs) appearing in Biophysical Reviews are decided the previous year after suitable consultation between the Biophysical Reviews' Editorial Board Members, the SI Guest Editorial Teams proposing the SIs, and the Springer Nature professional staff, with these SIs announced in Issue 1. However, these last 12 months of pandemic have been anything but typical with a lot of vagary as to whether meetings would (or even could) proceed. Not surprisingly, these uncertainties manifested within the SI lineups for 2021. However, with notable resilience, the scientific community has adapted and workarounds involving massive online meetings and small 
group Zoom/Skype calls have become common enough to constitute a 'new normal.' So, somewhat late, but with the spirit of hopefully returning to 'normal,' I list here the SIs for 2021 along with their SI Editors.

- The $20^{\text {th }}$ International IUPAB Congress (in conjunction with Brazilian Biophysical Society and Brazilian Society for Biochemistry and Molecular Biology) (SI Editors: Rosangela Itri, Mauricio Baptista, Richard Garratt, and Antonio Jose Costa-Filho)

- Cardiovascular Mechanobiology: State of the art and the newest insights into the role of mechanical forces in cardiovascular development, physiology, and disease (SI Editors Pamela: Swiatlowska and Thomas Iskratsch)

More details about these SIs can be gotten by contacting the authors directly, with their details found on the journal website: https://www.springer.com/journal/12551/editors

Your SI in Biophysical Reviews - The benefits To parallel a previous piece on the 'benefits of writing a review article' (Hall 2019), I thought it might be worthwhile ${ }^{3}$ to point out the benefits, provided to all potential Guest Editors, when organizing an SI within Biophysical Reviews.

i. Powerful friends: Biophysical Reviews is the sole journal of the International Union for Pure and Applied Biophysics (IUPAB). With sixty-four national biophysical society affiliates and with International Science Council (ISC) backing, IUPAB is the single international body championing and promoting biophysics at the policy, funding, and development levels. If your subject matter is biophysics, then Biophysical Reviews is the most pedigreed of the international journals in this area. More can be read about IUPAB and the ISC at the following web addresses:

ISC: https://council.science/about-us/

IUPAB: http://iupab.org/

ii. Professional services: Biophysical Reviews is jointly owned in a 50:50 arrangement between IUPAB and the Springer Nature Corporation. As one of the two largest scientific publishing houses in the world, Springer Nature is able to apply its considerable experience and professional services in the areas of manuscript handling, editorial processing, and article production. The journal has three full-time professional staff (an Editorial Assistant, a Production Manager, and a Journal Manager) along with a number of part-time professional staff involved in desktop publishing. As part of the Springer Nature commitment to ethics in publishing, the journal follows

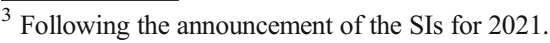

the Committee on Publishing Ethics (COPE) guidelines in its manuscript handling procedures (COPE 2021).

iii. Significant impact: Whilst pointing out that a journal's metrics do not necessarily always correlate with the scientific importance of the articles published within, it would be naive not to acknowledge that such metrics sway authors' perception and consideration for choosing a venue for publication. Within the search category of biophysics in the three major free-to-use journal assessment tools, Elsevier's Scopus-based SCIMAGO (SCIMAGO 2021), Leiden University's Center for Science and Technology Studies (CWTS 2021), and Google's Scholar Journal Rank (Scholar 2021), Biophysical Reviews is ranked as follows:

SCIMAGO $-12^{\text {th }}$ of 136 (based on SJR ranking) CWTS $-12^{\text {th }}$ of 112 (based on SNIP ranking) Scholar $-15^{\text {th }}$ overall (based on $\mathrm{h} 5$ ranking)

iv. Eye on cost: Increasingly, many legitimate journals operate on a mandatory open-access fee basis - a situation which can be problematic when not made clear to SI Editors and SI contributors beforehand ${ }^{4}$. In this regard, it is important to note the following about Biophysical Reviews fee structure. To maintain its accessibility to scientists from all corners of the world, the journal operates a hybrid open-access system, meaning that it has two tracks of payment available to all authors irrespective of location:

- Free to publish (no cost) option (0 Euros)

- Gold open access option ( 2500 Euros)

The free-to-publish option involves placing the published article behind a paywall for a period for 6 to 12 months before it then becomes freely available for download through PubMed Central. However, due to the fact that most large institutions carry the Springer catalogue of journals and that Springer operates special free access platforms in many less-developed countries, any serious downsides for authors electing to use the free to publish track are rarely seen in practice. Although the gold open access approach is the superior format for authors with funds to pay for it (also benefitting from Springer's post publication cross promotion services) both publishing tracks offer an excellent outcome and the free to publish option is invaluable for authors with more more modest funding arrangements.

\footnotetext{
${ }^{4}$ Organizing an SI involves considerable effort by the Guest Editors with great personal capital expended in persuading colleagues in their field to write an article to a deadline. Oftentimes, what started out as an altruistic scholarly endeavour can, if not managed carefully, end up alienating the SI Editors from the very community they wanted to unite under the thematic SI umbrella! With deadline tensions raging perhaps the coup de grâce in a working scientific relationship is delivered when the submitting author is required to pay (a previously unknown) three to five-thousand dollar publication charge by the journal managing the article production!
} 
xxii. Social media (Twitter/YouTube): The Biophysical Reviews journal operates two social media channels on Twitter and YouTube that it uses to promote each article 1 month after its initial publication. The journal has been an early advocate of an online sharing tool provided by Springer Nature, known as SharedIt, that allows for free reposting of each author's work in a completely unrestricted manner on any social media site (Hall 2017). Practically speaking, these free sharing links can be used to promote one's work to the maximum of the author's inclination and comfort level in doing so! The journal web page and the two social media sites operated by the journal are shown below.

Web: https://www.springer.com/journal/12551

Twitter: @BiophysicalRev1

YouTube: www.youtube.com/channel/UCzG_ 5MWmnrB2UBibtxs2DuA

vi. Two bespoke SI formats: At the planning and consultation stage, SI Editors are offered the option of two formats:

- Special issue format - a minimum of ten published articles (consisting of an Editorial, Commentaries, Letters, and short- and long-format review articles) with the entire issue devoted to the Special Issue topic.

- Issue focus format-in which a five-article space (consisting of a sub-Editorial, Commentaries, Letters, and short- and long-format review articles) is blocked off within a regular issue.

These two formats offer SI Editors a lot of flexibility in the design and construction of the SI with the one caveat being that due to the fact that they possess the entire Issue, full SIs must be committed to once chosen.

Concluding remarks Both prospective SI Editors, interested in compiling an SI, and prospective authors, interested in submitting a single review article to Biophysical Reviews, are encouraged to first broach the matter with either the Biophysical Reviews Chief Editor or their local Executive or Editorial Board Member. After discussion on the suitability of their topic, an appropriate timetable for their submission will be arranged in conjunction with the professional officers of the journal.

Acknowledgements I would like to thank Dr. Meran Lloyd-Owen and Prof. Adam S. Foster for comments made on an earlier draft of this manuscript. DH acknowledges funding associated with the receipt of a 'Tokunin' Assistant Professorship carried out at the WPI-Center for Nano Life Science, Kanazawa University. DH also acknowledges the
University of Aalto, for an appointment to their Affiliated Researcher Program carried out within the Department of Applied Physics.

As a final personal note, I would like to acknowledge the Nagoya Institute of Technology for an appointment to their 'Visiting International Scientist' program carried out at the Department of Life Science and Applied Chemistry (April 2020-March 2021). In rushing back from the USA in March of 2020, this placement allowed me to sustain myself over the short term and facilitated the circumstances that have allowed me to remain in Japan over the longer term-my special thanks to Prof. Hideki Kandori and the Administrative Staff at NITech!

\section{Declarations}

Conflict of interest The author declares no competing interests.

\section{References}

Bazhenova A, Gao F, Bolgiano B, Harding SE (2021) Glycoconjugate vaccines against salmonella enterica serovars and Shigella species: existing and emerging methods for their analysis. Biophys Rev 13(2) Current Issue

COPE (2021) https://publicationethics.org/. Accessed 10 Mar 2021

CWTS (2021) https://www.journalindicators.com/indicators. Accessed 10 Mar 2021

Hall D (2017) Innovations in publication: free sharing of all biophysical reviews' content. Biophys Rev 9(2):67-68. https://doi.org/10.1007/ s12551-017-0253-y

Hall D (2019) The benefits of writing a review. Biophys Rev 11(5):663666. https://doi.org/10.1007/s12551-019-00600-8

Hall D (2021) Biophysical reviews: slowly getting back to 'normal'. Biophys Rev 13(2) Current Issue

Itri R, Baptista M, Garratt R, Costa-Filho AJ (2021) Announcing the call for the special issue on the $20^{\text {th }}$ international congress of the International Union of Pure and Applied Biophysics (IUPAB) virtual meeting, October, 2021. Biophys Rev 13(2) Current Issue

Lamm O (1929) Zur theorie und methodik der ultrazentrifugierung. Z Phys Chem 143(1):177-190. https://doi.org/10.1515/zpch-192914318

Mabbitt PD (2021) Tools for the discovery of biopolymer producing cysteine relays. Biophys Rev 13(2) Current Issue. https://doi.org/ 10.1007/s12551-021-00792-y

Mohi SM, Saadon HL, Khalaf AA (2021) Laser tweezers as a biophotonic tool to investigate the efficacy of living sickle red blood cells in response to optical deformation. Biophys Rev 13(2) Current Issue. https://doi.org/10.1007/s12551-021-00790-0

Ovung A, Bhattacharyya J (2021) Sulfonamide drugs: structure, antibacterial property, toxicity and biophysical interactions. Biophys Rev 13(2) Current Issue Scholar (2021). https://scholar.google.com/ citations?view_op=top_venues\&hl=en\&vq=phy_biophysics. Accessed 10 Mar 2021

Scholar (2021) https://scholar.google.com/citations?view_op=top_ venues\&hl=en\&vq=phy biophysics. Accessed 10 Mar 2021

SCIMAGO (2021) https://www.scimagojr.com/journalrank.php? category=1304. Accessed 10 Mar 2021

Shonhai A (2021) Biophysical reviews 'meet the editor series'Addmore Shonhai. Biophys Rev 13(2) Current Issue. https://doi. org/10.1007/s12551-021-00794-w

Singh A, Phogat J, Yadav A, Dabur R (2021) The dependency of autophagy and ubiquitin proteasome system during skeletal muscle atrophy. Biophys Rev 13(2) Current Issue. https://doi.org/10.1007/ s12551-021-00789-7 
Svedberg T, Nichols JB (1923) Determination of size and distribution of size of particle by centrifugal methods. J Am Chem Soc 45(12): 2910-2917. https://doi.org/10.1021/ja01665a016

Svedberg T. and Pedersen K.O. (1940) The ultracentrifuge. The Ultracentrifuge

Vesperini D, Montalvo G, Qu B, Lautenschläger F (2021) Characterization of immune cell migration using microfabrication. Biophys Rev 13(2) Current Issue. https://doi.org/10.1007/s12551021-00787-9
Winzor DJ, Dinu V, Scott DJ, Harding SE (2021) Quantifying the concentration dependence of sedimentation coefficients for globular macromolecules: a continuing age-old problem. Biophys Rev 13(2) Current Issue

Publisher's note Springer Nature remains neutral with regard to jurisdictional claims in published maps and institutional affiliations. 